\title{
SINERGIA
}

REVISTA DO INSTITUTO DE CIÊNCIAS ECONÔMICAS, ADMINISTRATIVAS E CONTÁBEIS (ICEAC)

\section{TURISMO E CONTEÚDO GERADO PELO USUÁRIO: UMA ANÁLISE SOBRE O COMPORTAMENTO DO CONSUMIDOR NA INTERNET POR MEIO DE COMENTÁRIOS DE VIAGENS ONLINE}

\author{
LARISSA MIRAPALHETA MUNIZ \\ CARLOS ALBERTO FRANTZ DOS SANTOS
}

\begin{abstract}
RESUMO
Em razão dos Comentários Gerados pelos Usuários (CGU), é possível opinar sobre um produto ou serviço, bem como destinos de viagens, pois estes são disseminados rapidamente possibilitando aos viajantes o acesso a uma ampla quantidade de informações.O objetivo deste estudo é analisar a influência dos CGU na tomada de decisão do consumidor na escolha de um destino de viagem,como objetivos específicos: descrever o perfil dos respondentes; analisar a forma de utilização do CGU pelos respondentes; e identificar as variáveis que influenciam no processo de tomada dos respondentes a partir do CGU. Para a construção desta pesquisa,foi realizado levantamento do estado da arte sobre o CGU e levantamento bibliográfico sobre Tomada de Decisão e TICs. Esta pesquisa é de caráter quantitativo e utilizou o método Survey, sendo aplicados questionários online. Para analisar os dados, foi utilizada a técnica de estatística descritiva. Este estudo permitiu observar que os viajantes são mais influenciados que influenciadores e que os respondentes dão ênfase para comentários sobre custo e benefício na tomada de decisão de viagem. Foram sugeridas novas pesquisas voltadas para o turista, com aplicação de novas técnicas para compreender melhor a influência do CGU na tomada de decisão do viajante de um destino.
\end{abstract}

Palavras-Chave: Conteúdo Gerado pelo Usuário. Comportamento do Consumidor na Internet. Turismo.

\section{ABSTRACT}

Through User Generated Comments (UGC) it is possible to give opinions about a product or service, as well as travel destinations, as they are quickly disseminated, giving travelers access to a wide range of information. The objective of this study is to analyze the influence of the UGC in the decision making of the consumer in the choice of a travel destination, as specific objectives: to describe the profile of the respondents; to analyze the form of use of the UGC by the respondents; and to identify the variables that influence the process of taking the respondents from the UGC. For the construction of this research were carried out survey of the state of the art on the UGC and bibliographical survey on Decision Making and TICs. This research is quantitative and used the Survey method, and questionnaires were applied online. To analyze the data, the descriptive statistics technique was used. This study showed that travelers are more influenced than influencers and that respondents emphasize comments on cost and benefit when making travel decisions. New research aimed at the tourist was suggested, applying new techniques to better understand the influence of the UGC in the decision of the traveler of a destination.

Keywords: User Generated Content. Consumer Behavior on the Internet. Tourism.

Recebido em: 23-11-2018 Aceito em: 29-03-2019

\section{INTRODUÇÃO}

Os avanços tecnológicos dos meios de comunicação permitiram que as pessoas pudessem ter acesso à vasta quantidade de informações, enviar mensagens e, até mesmo, trocar conhecimentos. Desde essa perspectiva, a Internet tem sido uma ferramenta essencial para o turismo, principalmente para a divulgação de destinos turísticos (MARUJO, 2008). Ressalta-se, nesse contexto, que a web 2.0 influencia no comportamento do consumidor, principalmente por gerar a comunicação "boca a boca", permitindo a busca de informações, e, com sua evolução, acabou modificando a relação entre empresas e consumidores (TOMAS; MESCHGRAHW; ALCANTARA, 2012).

Com as ferramentas criadas na Internet, foi possível a aproximação entre os turistas e destinos, uma vez que assim se evidencia maior facilidade para encontrar as informações desejadas sobre cada local. A Internet permite que as pessoas se informem sobre o que elas desejam encontrar, visto que alguns turistas se sentem motivados a visitar um atrativo somente por ver uma imagem, outros preferem lugares por status e outros são ainda mais seletivos, ou seja, buscam locais diferentes daqueles procurados pela maioria das pessoas.

\footnotetext{
* Graduada em Turismo pela Universidade Federal do Rio Grande - FURG

"Mestre em Administração pelo PPGA/EA/UFRGS. Professor Assistente na Universidade Estadual do Rio Grande do Sul - UERGS
} 
O turismo é uma das atividades que mais movimenta a economia mundial, colaborando no desenvolvimento dos destinos, gerando emprego e criando mercados para atender às necessidades do indivíduo (BARBOSA, 2005). Atualmente, nota-se a presença de diversos canais para que os destinos/empresas possam ser divulgados e permitam um envolvimento dos consumidores, os quais podem fazer comentários sobre o local, o que possibilita que outros possíveis turistas observem a opinião dos consumidores a respeito do lugar desejado e obtenham maiores informações sobre o mesmo.

Segundo Lima Júnior et al., (2016), o turismo é algo intangível, e a Internet possibilitou que os produtos vendidos pudessem se tornar tangíveis, através de fotos, vídeos, sites e informações de viajantes compartilhadas. Devido às facilidades da Internet, os respondentes estão buscando, cada vez mais, informações sobre os destinos, pesquisando, em média, duas horas sobre sua viagem e lendo os comentários dos usuários para satisfazer a necessidade de descobrir novas informações (LIMA JÚNIOR et al., 2016). Sendo assim, faz-se necessário pesquisar como esses conteúdos influenciam a decisão do respondente na escolha de uma viagem, a fim de compreender melhor sobre como estes fatores influenciam o comportamento do consumidor no turismo.

O Conteúdo Gerado pelo Usuário (CGU) pode interferir em algumas variáveis externas expostas pelos autores Horner e Swarbrooke (2002), que apresentam os fatores internos e externos que influenciam na tomada de decisão do turista. Em seu modelo, nota-se que, dentre os fatores externos que influenciam a decisão do turista, não consta a Internet, tampouco o CGU, que, atualmente, pode estar influenciando na tomada de decisão do viajante

Atualmente, o CGU está presente em uma boa parcela da Internet. Dentro deste meio, podem ser encontrados os Comentários de Viagens na Internet (CVI) que possuem grande importância para o turismo, pois o consumidor compartilha suas experiências de viagens e serviços utilizados com outros usuários dessa mídia. Este assunto vem sendo pesquisado por Litvin et al. (2008), Arrigara e Levina (2008), Kaplan e Haenlein (2010), Terra (2011), Silva e Mendes Filho (2013), Andrade (2014) e Lima Júnior et al. (2016).

Embora existam estudos sobre CGU, eles são escassos, principalmente no Brasil. Não foram encontrados trabalhos que incluam o CGU e as suas relações com a tomada de decisão do viajante, portanto este artigo procura ampliar a discussão neste assunto ao estabelecer relações entre estes dois conceitos.

O objetivo geral deste trabalho é analisar a influência dos Conteúdos Gerados pelos Usuários na tomada de decisão de viagem e tem como objetivos específicos: descrever o perfil dos respondentes; analisar a forma de utilização do CGU pelos respondentes e identificar as variáveis que influenciam no processo de tomada dos respondentes a partir do CGU. Para atingir este objetivo, foi utilizado o método de pesquisa Survey, sendo aplicados questionários online e realizadas pesquisas em materiais bibliográficos, bem como levantamento do estado da arte em relação ao CGU.

Esta pesquisa, de cunho investigativo, justifica-se devido às já escassas de produções sobre este tema na área do turismo são em grande maioria direcionadas para as empresas, mostrando como o marketing de hotéis e agências de viagens podem atrair mais clientes, qual imagem as pessoas têm de um destino e como isso está atingindo os turistas. Ou seja, estas pesquisas não investigam a perspectiva do turista em saber como ele utiliza e reage aos comentários que estão sendo feitos sobre os destinos de seu interesse. Sendo assim, torna-se importante a realização deste estudo para contribuir no desenvolvimento desta área de conhecimento.

Mendes Filho e de Carvalho (2014) ressaltam a importância de entender de que maneira o CGU influencia na tomada de decisão e sugerem novas pesquisas a respeito deste tema com uma amostra maior do que a por eles realizada, com perfis variados para melhor representação (SILVA; MENDES FILHO, 2013).

Este trabalho contribui para entender como os CVI podem influenciar a tomada de decisão do viajante a partir da utilização dos Conteúdos Gerado pelo Usuário, contribuindo para preencher algumas lacunas ainda existentes neste campo de estudo: a relação do CGU entre a tomada de decisão do consumidor e a escolha de um destino de viagem.

\section{REFERENCIAL TEÓRICO}

O referencial teórico deste trabalho aborda os seguintes conceitos: Turismo e Internet, pesquisado por Lage (2000), Marujo (2008), Sousa (2014), Mtur (2014) e Mendes Filho e de Carvalho (2014). TICs, com pesquisas de Silva e Teixeira (2014), Silva e Mendes Filho (2015), Kietzmann et al., (2011), Buhalis e Law (2008), Cooper et al., (2007), Silva e Mendes Filho (2013) e Mendes Filho e Ramos (2002). CGU, pesquisado por Terra (2011), Litvin et al. (2008), Kaplan e Haenlein (2010), ambos citados por Andrade (2014), Lima Júnior et al. (2016), Lima Júnior e Mendes Filho (2015) e Carvão (2010). Tomada de Decisão, pesquisado por Pereira (2005), Horner e Swarbrooke (2002) e Cooper et al., (2007). 


\subsection{Turismo e internet}

Segundo Lage (2000 apud MARUJO, 2008), o turismo é uma atividade que está sofrendo grandes modificações devido à revolução da Internet, pois permite a comunicação entre prestadores de serviços e consumidores. Marujo (2008) relata que a Internet transmite as informações de forma rápida e permite que as organizações possam melhorar e criar novos produtos para oferecer ao consumidor.

A Internet está se tornando uma ferramenta cada vez mais importante na indústria do turismo, possibilita a divulgação de destinos, a reserva online e, até mesmo,a obtenção de novos conhecimentos sobre um destino ou serviço, permitindo que o turista sinta confiança no que está prestes a adquirir. Com essa ferramenta, os consumidores tendem a ser mais exigentes e a criarem maiores expectativas na escolha de um local para visitar (SOUSA, 2014). Os turistas buscam locais distantes de sua rotina, e a Internet se faz imprescindível na escolha do viajante. Além das informações encontradas sobre os destinos, nota-se a presença de imagens e comentários que podem influenciar na tomada de decisão do turista (SOUSA, 2014).

Para escolher um destino, o turista busca, além de relatos de amigos e parentes, informações que constam nos meios de comunicação (MARUJO, 2008). Estas informações, por sua vez, influenciam na escolha do turista a visitar um determinado local, visto que o mesmo procura diversificar lugares para seu descanso, entretenimento ou negócios. Segundo Mtur (2014), os relatos de familiares e conhecidos não estão sendo tão eficazes quanto à busca de informações pela Internet, que, por sua vez, tornou-se essencial para escolher um destino de viagem, crescendo $68,4 \%$ nos últimos anos. Os turistas buscam informações, sobretudo em redes sociais e, de acordo com a pesquisa efetuada pela consultoria Sparkle, $80 \%$ dos consumidores alegaram ser influenciados por imagens postadas no Facebook, cujo termo "viagem" é o mais discutido nesta rede (MTUR, 2014).

As informações obtidas pela Internet sobre os destinos afetam o emocional do potencial turista, fazendo com que ele sinta interesse e curiosidade sobre um destino. $\mathrm{O}$ uso da Internet acarreta na mudança de comportamento do consumidor, tornando-o mais exigente na hora de escolher um local para visitar. A evolução da Internet está tornando os destinos cada vez mais competitivos (MARUJO, 2008). A comunicação online entre consumidores possibilitou a troca de informações e a busca de outras maneiras de obtenção de informações sobre os produtos e serviços que desejam adquirir, auxiliando na escolha que melhor se adequa a sua necessidade (MENDES FILHO; DE CARVALHO, 2014).

Os autores ainda afirmam que as informações trocadas entre os consumidores afetam diretamente na tomada de decisão do turista sobre um destino e que, nos últimos anos, os sites de compra online estão se expandindo, aumentando a procura de destinos pela Internet, o que causa a diminuição da busca por agências de viagens tradicionais (MENDES FILHO; DE CARVALHO, 2014). Já o Mtur (2014) relata que a tecnologia auxilia as agências de viagens, pois a "expectativa é a de que soluções de realidade aumentada e realidade virtual, que unem fotos, vídeos, gráficos e informações manipuladas pelo computador, se transformem em ferramenta chave na hora de apresentar os destinos aos viajantes".

Assim, é possível notar a importância da Internet no cotidiano dos consumidores e empresas voltadas para o ramo turístico, facilitando na busca e escolha de um local para viagem através do que é disponibilizado nesse meio de informação, buscando atender à necessidade e à expectativa de cada indivíduo.

\subsection{Tecnologia de informação e comunicação como influenciador na escolha de viagens}

Atualmente, as organizações estão aderindo cada vez mais ao uso da Tecnologia da Informação e Comunicação (TICs), devido à necessidade de manterem-se sempre informadas (SILVA; TEIXEIRA, 2014). As TICs ganharam força com a globalização, atingindo todos os grupos sociais de modo distinto, acarretando na modernização das empresas e no melhor atendimento ao consumidor (SILVA; MENDES FILHO, 2015).

Dentro do marketing digital, estão as mídias sociais, que, por sua vez, buscam tecnologias para que sejam criadas plataformas interativas, as quais permitem que pessoas possam compartilhar e discutir assuntos que os usuários produzem. Com o aumento da utilização das mídias sociais, o marketing "boca a boca" se tornou tangível, influenciando o consumidor e interferindo o seu comportamento para a tomada de decisões (KIETZMANN et al., 2011). Ou seja, "as mídias sociais não apenas ampliaram a disseminação de informações sobre viagens e destinos, mas permitiram o compartilhamento de recomendações, dicas e experiências de viagem" (LEHMANN, 2013, p. 66).

Segundo Buhalis e Law (2008 apud BOARIA, 2013), as TICS são uma ferramenta que permite ao viajante acessar uma ampla quantidade de informações, facilitando a busca dessas informações sobre o destino desejado. A atividade turística sofre grande influência das TICs, pois, devido a sua comunicação eficaz, não só as empresas, como os próprios consumidores, beneficiam-se com o seu desenvolvimento (COOPER et al., 2007). 
Com o avanço das TICs, a sociedade adquiriu diversas possibilidades para se tornar mais informada e isso afeta diretamente os agentes de turismo, pois as empresas têm maior facilidade em se comunicar (SILVA; MENDES FILHO, 2013). Os mesmos autores ainda relatam que as TICs, a Internet e o turismo formam uma parceria, já que, com a facilidade em encontrar as informações necessárias, o turista pode planejar sua viagem de forma segura (SILVA; MENDES FILHO, 2013).

Mendes Filho e Ramos (2002) afirmam que a Tecnologia da Informação permite que o consumidor possa realizar, de forma rápida, alguns serviços, tais como reservar passagens ou realizar o check-out do hotel, assim sendo, as TICs diminuem, consideravelmente, o tempo utilizado pelo turista na realização de alguns serviços, visto que o tempo é algo essencial para a competitividade do turismo.

Dessa forma, entende-se que as TICs permitem que o consumidor tenha mais segurança ao adquirir um pacote de viagem em uma agência ou até mesmo ir a algum local por conta própria, sabendo o que poderá experienciar no local, pois, ao ter acesso às TICs, o consumidor poderá encontrar destinos e roteiros de modo que possa suprir sua necessidade e atingir maior satisfação.

\subsection{Conteúdo gerado pelo usuário e comunicação "boca a boca" online}

Nesta seção, serão abordados dois conceitos: comunicação "boca a boca" online e Conteúdo Gerado pelo Usuário. Por serem assuntos novos, suas definições ainda não estão consolidadas na literatura e não há um consenso entre as duas terminologias. Sendo assim, torna-se relevante abordá-los neste tópico. Nesta pesquisa, foi escolhido o termo CGU devido aos principais autores utilizados nesta pesquisa (Lima Júnior e Mendes filho) trabalharem com esta terminologia.

Autores como Terra (2011), Litvin et al.. (2008), Kaplan e Haenlein (2010), ambos citados por Andrade (2014), Lima Júnior et al. (2016), utilizam o termo comunicação "boca a boca" online. Por sua vez, Silva e Mendes Filho (2013) e Arrigara e Levina (2008), Lima Júnior e Mendes Filho (2015) e Carvão (2010) definem como CGU.

Segundo Terra (2011), a comunicação "boca a boca" online começa a partir de opiniões pessoais divulgadas na Internet e isso acarreta na sua disseminação. Os respondentes divulgam seus comentários em suas redes de contato, promovendo a dispersão desses conteúdos, propagando-se rapidamente. Já para Andrade (2014), o surgimento da comunicação "boca a boca" online deu-se a partir da criação de blogs, permitindo às pessoas expressarem suas opiniões a respeito de um produto, marca ou serviço prestado. Com o avanço da tecnologia e a criação de redes sociais, tornou-se possível compartilhar essas opiniões e comentários com outros usuários.

Litvin et al., (2008, apud ANDRADE, 2014) conceituam o "boca a boca" online (e-WOM ou electronic Word of Mouth) como comunicações feitas de modo informal sobre o uso e características de um serviço ou produto que é levado aos consumidores através da Internet. Ou seja, o "boca-a-boca" virtual é realizado através de comentários de consumidores em meio eletrônico (KAPLAN; HAENLEIN, 2010 apud ANDRADE, 2014). Os efeitos do e-WOM influenciam no comportamento do consumidor conforme sua experiência, seja ela positiva, seja negativa, com os serviços e produtos adquiridos (RONG et al.,2012 apud BOARIA, 2013).

Por sua vez, os autores Lima Júnior et al.,(2016) utilizam o termo CGU e destacam exemplos como: comentário de usuário, redes sociais, blogs, podcasts e Really Simple Syndication (feeds RSS). Estes canais, assim como todas as mídias geradas pelo consumidor, permitem que os usuários possam gerar conteúdos e exporem suas opiniões a respeito de produtos na Internet, influenciando outros possíveis consumidores a adquirir ou não determinado produto. Segundo Arrigara e Levina (2008), o CGU não pode ser formado por empresas, mas apenas pelo público em geral. O CGU permite que os utilizadores possam se informar mais sobre os destinos, observando imagens, opiniões ou vídeos de outros usuários antes de escolher um destino (SILVA; MENDES FILHO, 2013).

Através do CGU, os destinos também podem ser divulgados, seja por meio de redes sociais, seja por sites institucionais. Muitas pessoas possuem acesso à Internet e entram em contato com esse conteúdo, sendo informadas sobre os destinos desejados. Esta comunicação "boca a boca" online permite a publicidade dos destinos, mesmo sem intenção, pois comentam sobre o destino e sua atividade turística (LIMA JÚNIOR; MENDES FILHO, 2015).

O CGU desenvolve uma fonte de informação ampla para uso dos potenciais visitantes de um destino, seja em redes sociais, seja em sites institucionais, identificando o grau de satisfação do turista e suas experiências, compartilhando na Internet fotos e informações sobre um destino. Embora estes usuários não representem a totalidade de visitantes de um destino, são caracterizados como um segmento crescente (CARVÃO, 2010).

Carvão (2010) ainda relata que é possível acompanhar os CGU e verificar algumas questões como as intenções, as motivações e as percepções dos turistas em relação a um destino, auxiliando a segmentar o público que utiliza produtos/serviços turísticos. 
Analisando estes conceitos, pode-se observar que o "boca a boca online" possui grande influência no momento da escolha de um destino de viagem devido ao consumidor ter acesso às diversas experiências de outros consumidores, permitindo observar todos os pontos positivos e negativos de determinado local.

\subsection{Fatores que influenciam na tomada de decisão e suas relações com CGU}

O comportamento do consumidor é um assunto que engloba diversas questões, dentre elas, encontrase o processo de tomada de decisão. Segundo Horner e Swarbrooke (2002), o comportamento do consumidor no ramo do turismo está ligado ao seu emocional, pois os consumidores buscam a fuga do seu cotidiano. Os viajantes buscam manterem-se mais informados quando se trata de turismo pelo fato de sua intangibilidade, assim aprofundando a busca de informações para tomar sua decisão. Sendo assim, Pereira (2005) destaca que é de extrema importância conhecer quais são as características do turista, permitindo que o turismo cresça de modo harmônico, visto que o mesmo permite a geração de renda, a conservação da cultura e do ambiente, a socialização de pessoas e a diminuição das desigualdades existentes em um local.

Segundo Horner e Swarbrooke (2002), o comportamento do consumidor é complexo e envolve alguns aspectos, tais como:

- Comprometimento do consumidor com a decisão de compra de um serviço ou produto, em que o indivíduo pesquisa sobre o que está prestes a adquirir;

- Insegurança devido à intangibilidade dos serviços, o consumidor passa a buscar formas que garantam suas escolhas, através de fontes de informação;

- Significado emocional como a escolha de viagens nas férias ou a aquisição de outros bens;

- Influência de outras pessoas no processo decisório no que se refere ao turismo;

- Decisão a longo prazo, em que o consumidor pode pensar de um modo ao adquirir sua viagem com antecedência e pensar de outro modo no momento da viagem;

- Busca de informações: As escolhas afetam o emocional do consumidor, isso faz com que, antes que adquirir um produto ou serviço, o indivíduo busque mais informações para tomar sua decisão, seja informar-se com outras pessoas, seja através da mídia;

Os mesmos autores ainda ressaltam que a escolha de um destino de viagem não é tão simples. O processo decisório envolve diversos fatores internos e externos que influenciam na tomada de decisão do consumidor ao planejar sua viagem, os quais serão mostrados na figura abaixo. Nota-se que a figura 1 representava, no ano de 2002, os fatores externos e internos que influenciam na aquisição de serviços turísticos. Porém, atualmente, existem outros fatores que poderiam ser inseridos, sendo interessante atualizar o mesmo, inserindo novas variáveis. A Internet é uma variável que vem ganhando forças nos últimos anos e poderia se encaixar juntamente a esses fatores externos; conforme este estudo, a mesma também pode influenciar o consumidor.

FIGURA 1 - Fatores que influenciam a decisão relativa às férias.

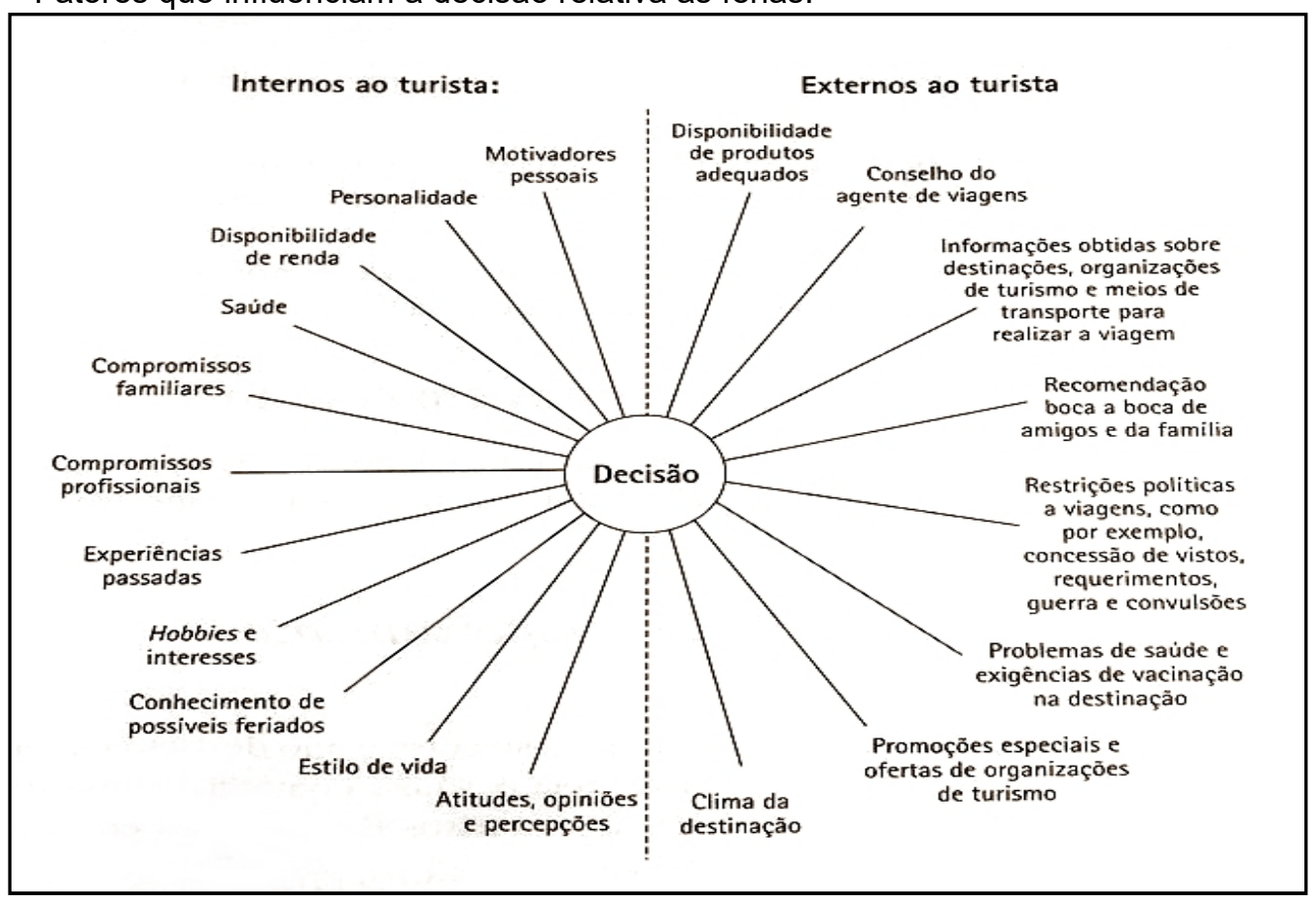

FONTE: Horner e Swarbrooke (2002). 
Segundo Cooper et al., (2007), pode-se entender que cada indivíduo possui percepções e motivações diferentes, levando cada pessoa a tomar sua decisão sobre viagens. Sendo assim, faz-se necessário entender como os consumidores tomam essas decisões, analisando suas necessidades e segmentos de mercado.

Cooper et al. (2007) ainda relatam que o processo de decisão de compra no ramo do turismo é composto pelas seguintes etapas que podem ou não ser totalmente contempladas:

- Surgimento da necessidade;

- Reconhecimento: o viajante recebe estímulos internos e externos para viajar;

- Nível de envolvimento: a partir do reconhecimento da necessidade, o viajante busca informações para eleger e saber mais sobre um destino;

- Identificação e avaliação de alternativas: o viajante passa a analisar as alternativas de viagem de acordo com suas necessidades e recursos disponíveis;

- Decisão de compra: a decisão é realizada após o viajante observar se o destino se enquadra nas características desejadas;

- Comportamento após a compra: é a necessidade de o viajante reafirmar a confiança sobre o produto, podendo ser disponibilizados contatos para o consumidor tirar suas dúvidas a respeito do produto.

A decisão do indivíduo sobre uma viagem não é apenas definir um destino para viagem, decide ao longo de sua viagem, seja sobre serviços de alimentação e meios de hospedagens, seja quais locais que irão visitar (HORNER; SWARBROOKE, 2002).

Estes conceitos sobre decisão de compra (COOPER et al., 2007; HORNER e SWARBROOKE, 2002) possuem pontos que se relacionam com os CGUs na medida em que as informações dos comentários podem contribuir para o aumento do conhecimento do viajante e, consequentemente, para uma tomada de decisão mais consciente sobre o destino e/ou atrativo turístico.

De forma específica, os CGUs se relacionam com o processo de decisão proposto por Cooper et al. (2007) a partir do momento em que os CGUs podem ser um dos estímulos da etapa do Reconhecimento, mas, principalmente, uma das fontes de informação das etapas Nível de Envolvimento e Identificação e Avaliação de Alternativas para embasar a etapa Decisão de Compra. Além disso, os CGUs podem expressar o Comportamento após a Compra.

As aproximações teóricas entre CGUs e os conceitos de Horner e Swarbrooke (2002) ocorrem em diversos aspectos. A recomendação "boca a boca" de amigos e família, a qual consta na figura 1, não se limita apenas a estas variáveis; o CGU também pode ser um modo de "boca a boca" de forma virtual. Outra possibilidade está na contribuição dos CGUs para as "informações obtidas sobre destinações, organizações de turismo e meios de transporte para realizar a viagem". Os CGUs podem reduzir a Insegurança gerada pela intangibilidade dos serviços, bem como influenciar pessoas no processo decisório no que se refere ao turismo. Ao contribuir em todos estes aspectos do processo decisório, os CGUs são importantes para a tomada de decisão a longo prazo, em que o consumidor pode pensar de um modo ao adquirir sua viagem com antecedência. Portanto, a busca de informações com outras pessoas ou através da mídia sintetiza a contribuição dos CGUs para o turista tomar sua decisão.

\section{PROCEDIMENTOS METODOLÓGICOS}

Para a realização deste artigo, foi utilizado o método Survey, que, por sua vez, consiste em responder "como", "quanto" e "por que" de algo acontecer (FREITAS et al., 2000). Inicialmente, realizou-se um levantamento bibliográfico, complementado por um estudo sobre o estado da arte sobre as publicações nacionais sobre CGU.

Esta pesquisa investigativa é de cunho quali-quantitativo e possui amostragem por conveniência, através de sondagem eletrônica, ou seja, foram enviados questionários a partir da rede de contatos dos pesquisadores, pois a cidade onde os pesquisadores residem não possui atrativos com ampla divulgação online, o que poderia limitar a amostra da pesquisa. Pelo fato da limitação geográfica e pela sazonalidade, não foi possível escolher um destino específico, porquanto, no período da coleta dos dados (setembro), não há grande demanda de turistas na região para realizar esta pesquisa. Este estudo classifica-se como descritivo, verifica e descreve a influência do CGU na tomada de decisão de viagem, assim como identifica o perfil do turista que utiliza este recurso, que tipo de comentários faz o viajante tomar sua decisão e o tipo de turismo praticado em sua última viagem a partir do CGU.

$\mathrm{O}$ instrumento de coleta de dados possui duas seções. A primeira tem como objetivo identificar como e com qual frequência o CGU pode influenciar o turista. Esta seção apresenta questões sobre que tipos de comentários os usuários buscam para tomar sua decisão, quantidade, frequência e tempo de utilização dos comentários e se estes influenciam o turista, tipo de turismo praticado, tempo de experiência com Internet, websites utilizados e se costuma compartilhar sua opinião com outros usuários. A segunda seção do questionário busca saber qual é o perfil dos respondentes. As seções foram adaptadas de Lima Júnior et al.(2016) e de Andrade (2014), respectivamente. 
A coleta de dados foi precedida de um questionário pré-teste, realizado no dia 01 de setembro de 2016, com três turismólogas, docentes, com mestrado na área de Turismo, que auxiliaram no desenvolvimento e nos ajustes iniciais do instrumento. Após as alterações sugeridas, foram aplicados dois pré-testes para seis universitários da Universidade Federal do Rio Grande, que declararam responder, sem maiores dificuldades, sobre as questões propostas. Três perguntas foram reelaboradas e novamente 0 questionário foi aplicado no dia 07 de setembro, ajustando as questões para, posteriormente, aplicá-lo de forma definitiva. Após realizar os pré-testes, o instrumento foi aplicado entre os dias 09 e 25 de setembro de 2016 , tendo como retorno um total de 323 respostas. Após a coleta de dados, procedeu-se ao tratamento preliminar dos dados, permitindo a obtenção de resultados mais acurados, consequência da maior familiaridade com as características dos dados e relações entre as variáveis, o que permitiu a eliminação de alguns "ruídos" presentes nos dados brutos (HAIR et al., 2009).

A análise incluiu a identificação de possíveis outliers e missing data (ou seja, alguns respondentes colocaram a cidade em que residem no local da idade, outros alegaram nunca ter usado o CGU, mas, posteriormente, afirmaram usar frequentemente). No final deste processo, foram obtidos 246 questionários submetidos para a análise realizada com o software Excel. Para a análise dos dados, foi realizada a estatística descritiva e gráficos em planilha eletrônica, que, por sua vez, foram analisados em percentuais e frequência de cada uma das variáveis questionadas.

\section{ANÁLISE DOS RESULTADOS}

Esta seção apresenta os resultados da pesquisa, respondendo aos seguintes objetivos propostos nesta pesquisa: descrever o perfil dos respondentes; analisar como são utilizados os CGU; e identificar quais variáveis influenciam no processo de tomada de decisão dos respondentes.

\subsection{Descrição do perfil dos respondentes}

Segue abaixo, na tabela 1 , o perfil dos respondentes desta pesquisa.

TABELA 1 - Perfil Sociodemográfico.

\begin{tabular}{|c|c|c|c|}
\hline VARIÁVEIS & GÊNERO & FAIXA ETÁRIA & ESTADO CIVIL \\
\hline Feminino & $59 \%(n=144)$ & & \\
\hline Masculino & $41 \%(n=102)$ & & \\
\hline De 16 a 20 anos & & $17 \%(n=43)$ & \\
\hline De 21 a 30 anos & & $53 \%(n=130)$ & \\
\hline De 31 a 40 anos & & $18 \%(n=45)$ & \\
\hline De 41 a 50 anos & & $7 \%(n=18)$ & \\
\hline De 51 a 63 anos & & $4 \%(n=11)$ & \\
\hline Solteiro & & & $73 \%(n=180)$ \\
\hline Casado/União Estável & & & $23 \%(n=56)$ \\
\hline Divorciado/Viúvo & & & $4 \%(n=10)$ \\
\hline & ESCOLARIDADE & RENDA MENSAL & ESTADO EM QUE RESIDE \\
\hline Ensino médio & $20 \%(n=49)$ & & \\
\hline Ensino Técnico & $7 \%(n=18)$ & & \\
\hline Graduação & $54 \%(n=132)$ & & \\
\hline Pós-Graduação & $19 \%(n=47)$ & & \\
\hline Até 2 salários mínimos & & $34 \%(n=83)$ & \\
\hline De 2 a 4 salários mínimos & & $29 \%(n=71)$ & \\
\hline De 4 a 10 salários mínimos & & $24 \%(n=60)$ & \\
\hline De 10 a 20 salários mínimos & & $8 \%(n=20)$ & \\
\hline Mais de 20 salários mínimos & & $5 \%(n=12)$ & \\
\hline Centro-Oeste & & & $3 \%(n=7)$ \\
\hline Nordeste & & & $6 \%(n=14)$ \\
\hline Norte & & & $2 \%(n=4)$ \\
\hline Sudeste & & & $12 \%(n=29)$ \\
\hline Sul & & & $78 \%(n=192)$ \\
\hline
\end{tabular}

FONTE: Elaborado pelos autores (2018). 
De acordo com a tabela 1, observa-se o perfil sociodemográfico dos respondentes. Pode-se notar a predominância de respondentes do gênero feminino, sendo em $59 \%$ da totalidade do questionário. Os respondentes possuem uma média de 37,6 anos de idade e $73 \%$ da amostra declararam ser solteiros.

Em relação à renda mensal, observa-se que as classes sociais dos respondentes são, em grande parte, de classe "E", que representa até 2 salários mínimos. Em segundo lugar, a classe "D" representada por quem recebe de 2 a 4 salários, seguido da classe "C" (de 4 a 10 salários mínimos), "B" (de 10 a 20 salários mínimos) e A (Mais de 20 salários mínimos). Quanto à escolaridade, $54 \%$ da amostra possui graduação e $19 \%$ pós-graduação. Apenas $7 \%$ da amostra possui ensino técnico e $20 \%$ ensino médio.

Em relação à região que o respondente reside, o instrumento contou com respondentes das 5 regiões do país, porém $78 \%$ da amostra são respondentes da região Sul, devido ao instrumento ter sido aplicado a partir dos contatos dos pesquisadores.

Segundo a pesquisa de Okazaki e Hirose (2009 apud BOARIA, 2013), as mulheres são mais propensas a buscar e trocar informações WOM. Outras características buscadas pelos consumidores como idade, escolaridade e renda são fatores essenciais na busca de informações sobre suas viagens.

\subsection{Análise do uso do conteúdo gerado pelo usuário}

Esta subseção analisa como ocorre o uso do CGU, apresentando a frequência de utilização, o tempo gasto, a quantidade de comentários analisados, os sites utilizados, os tipos de turismo, entre outras variáveis.

No instrumento aplicado, foi questionada a experiência dos respondentes com Internet. $\mathrm{O}$ gráfico 1 mostra que todos respondentes já possuem conhecimento com a Internet: $52 \%$ há mais de 10 anos; $28 \%$ utilizam de 8 a 10 anos; $17 \%$, de 5 a 7 anos e apenas $2 \%$ utilizam a Internet de 2 a 4 anos. Pode-se concluir que os indivíduos participantes desta pesquisa já possuem experiência com Internet, ocupando $97 \%$ da amostra que utiliza a Internet há mais de 5 anos.

GRÁFICO 1 - Tempo de experiência com a Internet

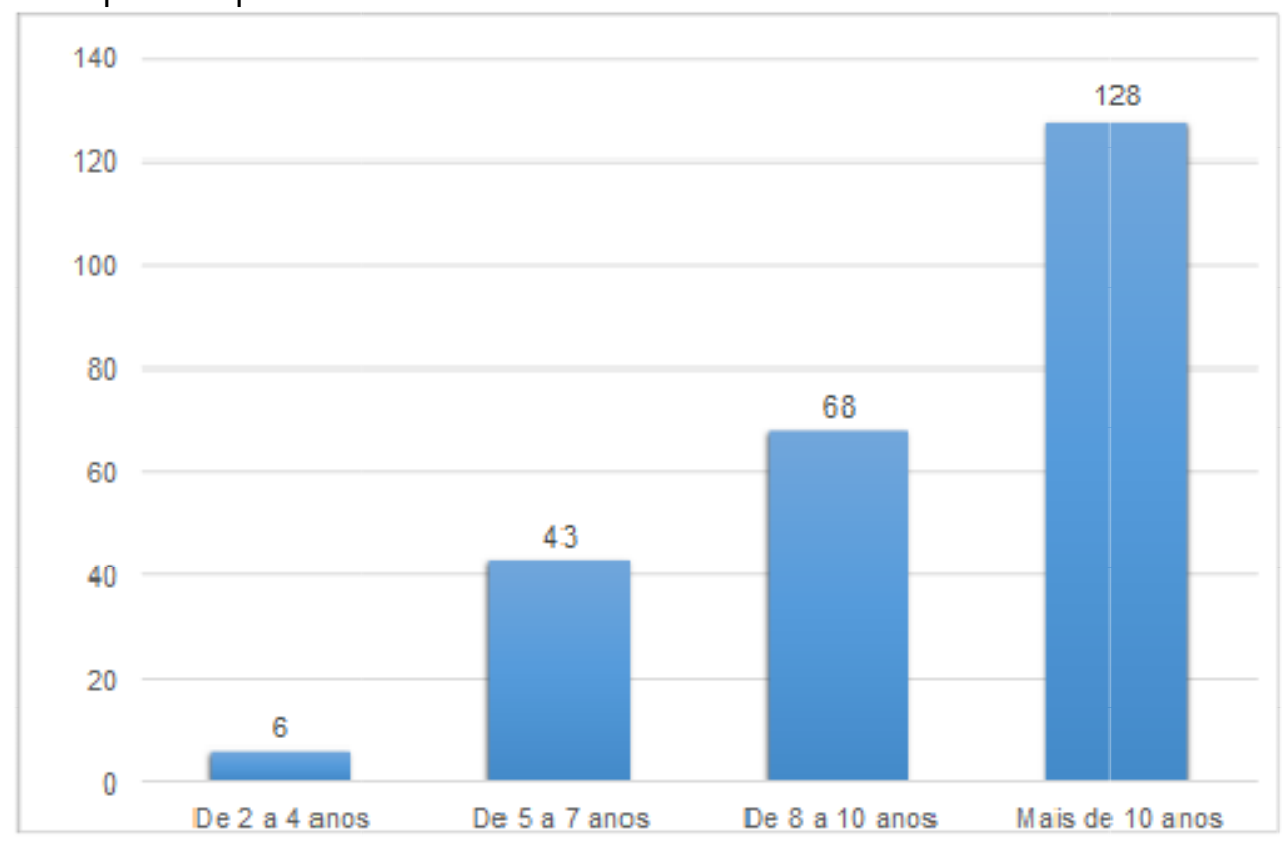

FONTE: Elaborado pelos autores (2018).

Neste trabalho, foi observado um acentuado número de respondentes que já utilizaram CGU para planejar sua viagem, sendo um total de $93 \%$ da amostra obtida. Este é um dado relevante que evidencia a importancia do CGU, tendo em vista o elevado percentual de viajantes que já utilizaram esses conteúdos alguma vez para escolher um destino de viagem. No que diz respeito à tabela 2 (abaixo), é possível verificar se o respondente já utilizou CVI e se estes influenciam na sua decisão.

TABELA 2 - Utilização e influência dos CGU

\begin{tabular}{|l|c|c|}
\hline Variáveis & & \\
\hline Você já utilizou comentários de viagens na Internet? & $93 \%(\mathrm{n} .=229)$ & $7 \%(\mathrm{n} .=17)$ \\
\hline $\begin{array}{l}\text { Os Comentários de viagem online influenciam na } \\
\text { escolha de um destino? }\end{array}$ & $85 \%(\mathrm{n} .=210)$ & $15 \%(\mathrm{n} .=36)$ \\
\hline
\end{tabular}

FONTE: Elaborado pelos autores (2018). 
Embora haja um acentuado número de pessoas que já utilizaram CGU, nota-se, na tabela 3, que não são todos os respondentes que acreditam serem influenciados pelos Conteúdos Gerados pelo Usuário, sendo $85 \%$ da amostra. O restante da amostra (15\%) afirma que o CGU não influencia na escolha de um destino de viagem.

A pesquisa de Lima Júnior et al. (2016) aponta neutralidade no que diz respeito à influência dos CVI, diferentemente deste estudo, o qual ressalta um aumento da influência sobre o consumidor em relação ao estudo de Lima Júnior et al. (2016). O gráfico abaixo apresenta a frequência em que os respondentes utilizam esta ferramenta; $43 \%$ usam às vezes, $26 \%$ frequentemente, $12 \%$ buscam sempre, mesmo percentual para raramente, e apenas $7 \%$ alegam nunca ter utilizado os CVI.

GRÁFICO 2 - Frequência que os respondentes utilizam o CGU.

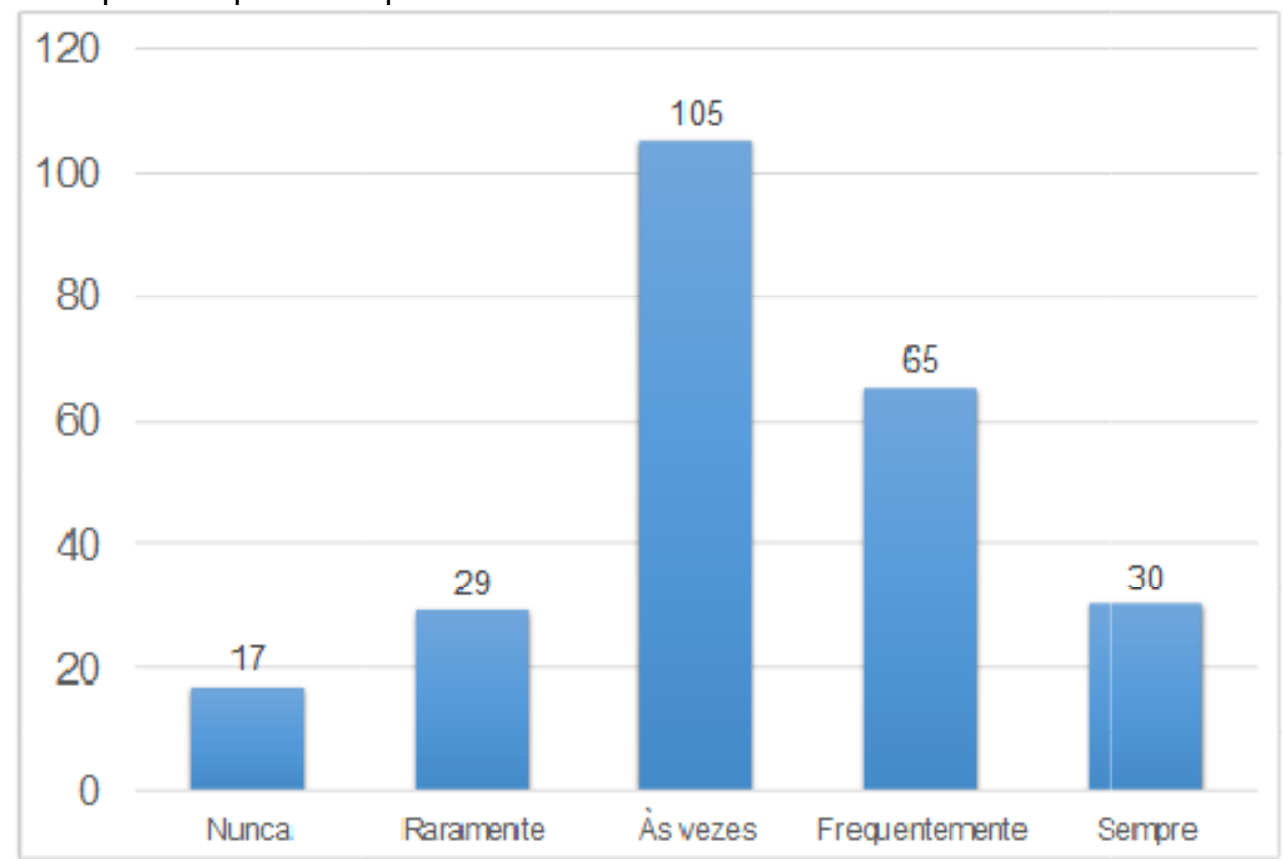

FONTE: Elaborado pelos autores (2018).

Comparando com a pesquisa de Lima Júnior et al. (2016), pode-se notar que o número de indivíduos que nunca utilizaram os CGUs aumentou. Os respondentes não estão buscando esta ferramenta com tanta frequência, aumentando o número de pessoas que utilizam às vezes.

No gráfico 3 (abaixo), pode ser observado que os usuários analisam uma quantidade considerável de comentários, sendo $68 \%$ da amostra que visualizam até 15 Conteúdos Gerados pelos Usuários. Este percentual está dividido em três categorias: $20 \%$ de 1 a 5 comentários, $25 \%$ de 6 a 10 comentários e $23 \%$ de 11 a 15 comentários lidos para a escolha de um destino. Os demais são $12 \%$ que visualizam mais de 30 comentários, seguido de $10 \%$ de 21 a $25,1 \%$ de 26 a 30 e $7 \%$ não utilizam esta ferramenta. 
GRÁFICO 3 - Quantidade de CVI visualizados.

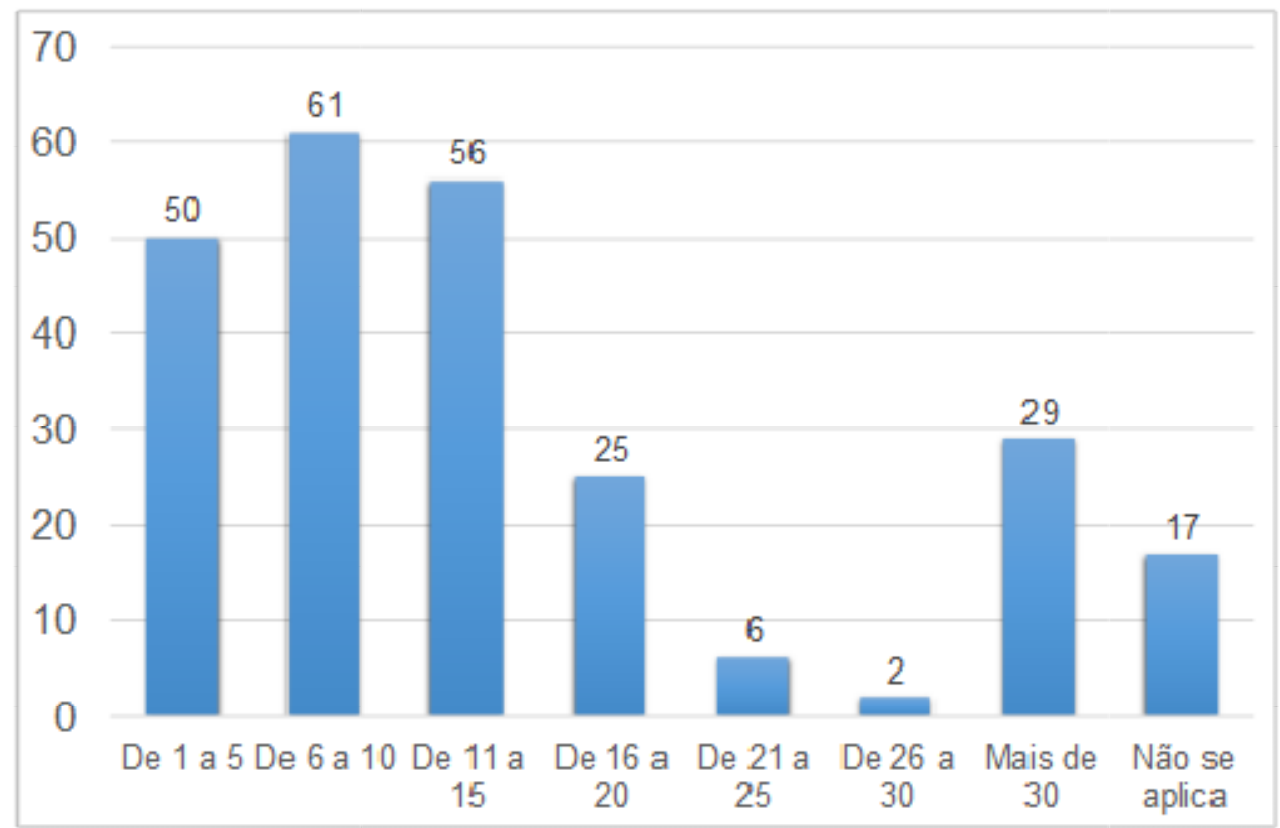

FONTE: Elaborado pelos autores (2018).

Um comparativo com a pesquisa de Lima Júnior et al. (2016) mostra que os resultados são parecidos nas duas pesquisas. Essa comparação mostra que os usuários apresentam um "limite" de aproximadamente vinte comentários em suas pesquisas.

Abaixo, o gráfico 4 mostra o tempo utilizado na busca de CVI. Foi identificado que $26 \%$ da amostra despende menos de 30 minutos de seu tempo na busca de CGU; outros $38 \%$ gastam de uma a duas horas, $13 \%$, de duas a três horas. O restante da amostra possui um percentual de $6 \%$ dos respondentes que dispõem do seu tempo com os Conteúdos Gerados pelo Usuário em torno de três a quatro horas, $2 \%$, de quatro a cinco horas, $7 \%$ alegam utilizar mais de cinco horas na busca das informações sobre o destino e, por fim, $8 \%$ não se encaixam nas alternativas ou não utilizam a ferramenta.

GRÁFICO 4 - Tempo utilizado pelos respondentes com os CVI.

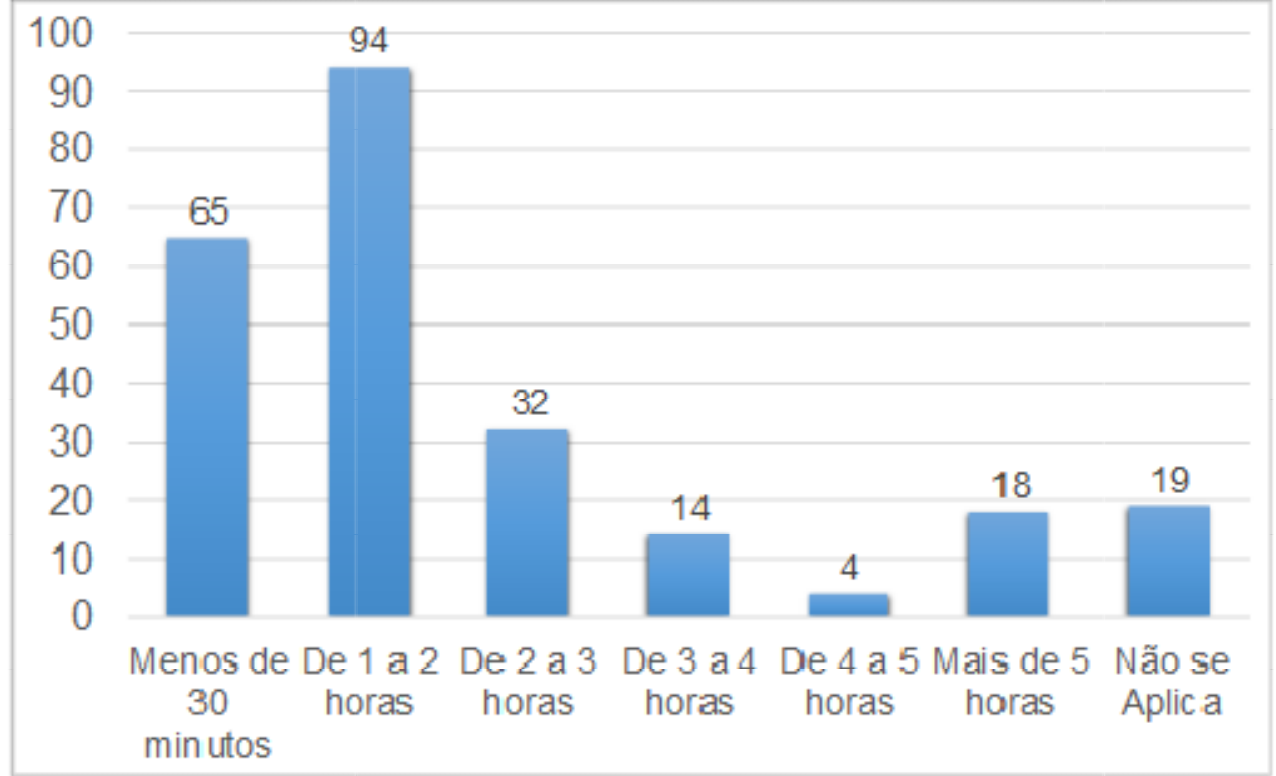

FONTE: Elaborado pelos autores (2018).

Quanto ao tempo utilizado com esta ferramenta, comparado a outras pesquisas, este permanece semelhante, sendo uma grande parcela da amostra que dispende até duas horas de seu tempo para escolher um destino de viagem. Ou seja, há a busca de CGU, porém, em menor tempo, os respondentes conseguem tomar sua decisão de viagem. 
Abaixo, o gráfico 5 apresenta os websites mais utilizados comos fontes de informações dos respondentes. Dentre eles, destacam-se: Facebook (59\%) TripAdivisor (51\%), Decolar (45\%) e Blogs de viagem tendo um percentual de $39 \%$.

GRÁFICO 5 - Websites utilizados na busca de informações.

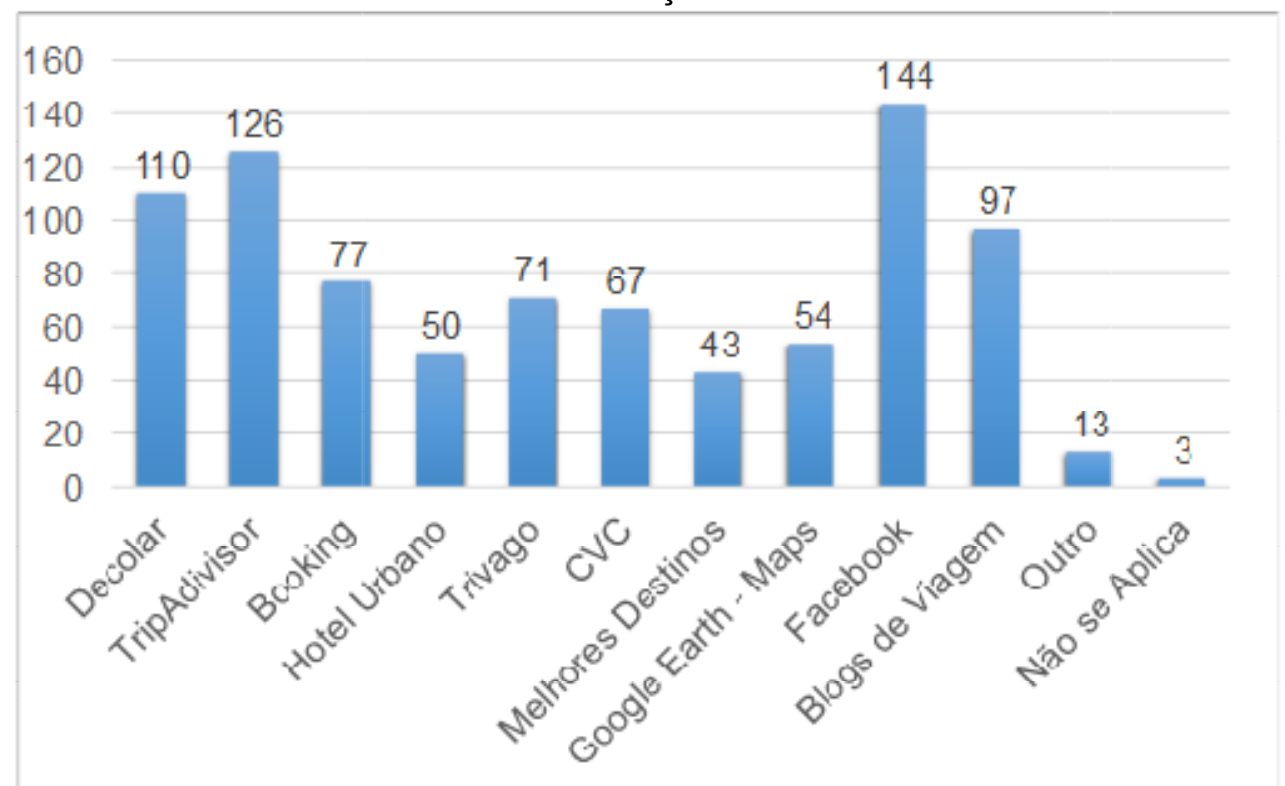

FONTE: Elaborado pelos autores (2018).

Os respondentes citaram outros sites e aplicativos como: Instagram, Mochilando, Airbnb, Convention Bureau, E-Dreams y Tubillete, Skyscanner, Mochileiros e Peixe Urbano que são utilizado na busca de informações sobre destinos para viagem.

No gráfico 6, apresenta o tipo de turismo que os respondentes praticaram em sua última viagem a partir dos CVI. Destacam-se: Turismo de Sol e Praia (26\%); Turismo Cultural $(20 \%)$ e Turismo Social (12\%). Os demais tipos de turismo tiveram um percentual abaixo de $9 \%$.

GRÁFICO 6 - Tipo de turismo praticado a partir dos CGU.

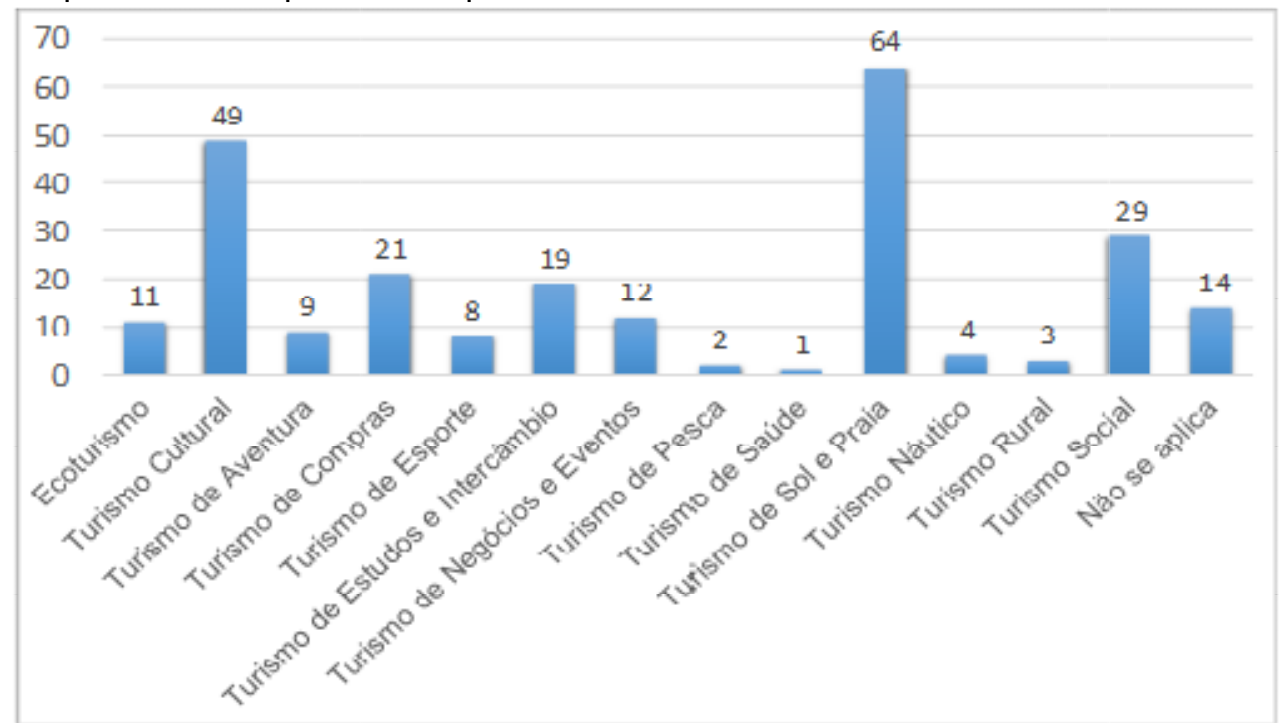

FONTE: Elaborado pelos autores (2018).

Tanto esta pesquisa quanto a pesquisa de Maia (2014) indicam que a grande maioria prefere ou prática turismo de sol/praia e turismo cultural, sendo $46 \%$ dos respondentes da pesquisa de Maia (2014) que preferem turismo de sol e praia, e $19 \%$ escolheu turismo cultural. Os demais tipos são em menor percentual, assim como esta pesquisa.

Já no gráfico 7, apresentado logo abaixo, nota-se que, após sua viagem, grande parte dos indivíduos não possuem o hábito de compartilhar suas experiências com outros usuários. Sendo $31 \%$ dos 
respondentes compartilham às vezes, $30 \%$ raramente e $23 \%$ nunca compartilha. Nota-se um baixo percentual dos indivíduos que compartilham frequentemente, sendo $10 \%$ e apenas $6 \%$ compartilham suas experiências a cada viagem realizada.

GRÁFICO 7 - Compartilhamento de informações pós viagem.

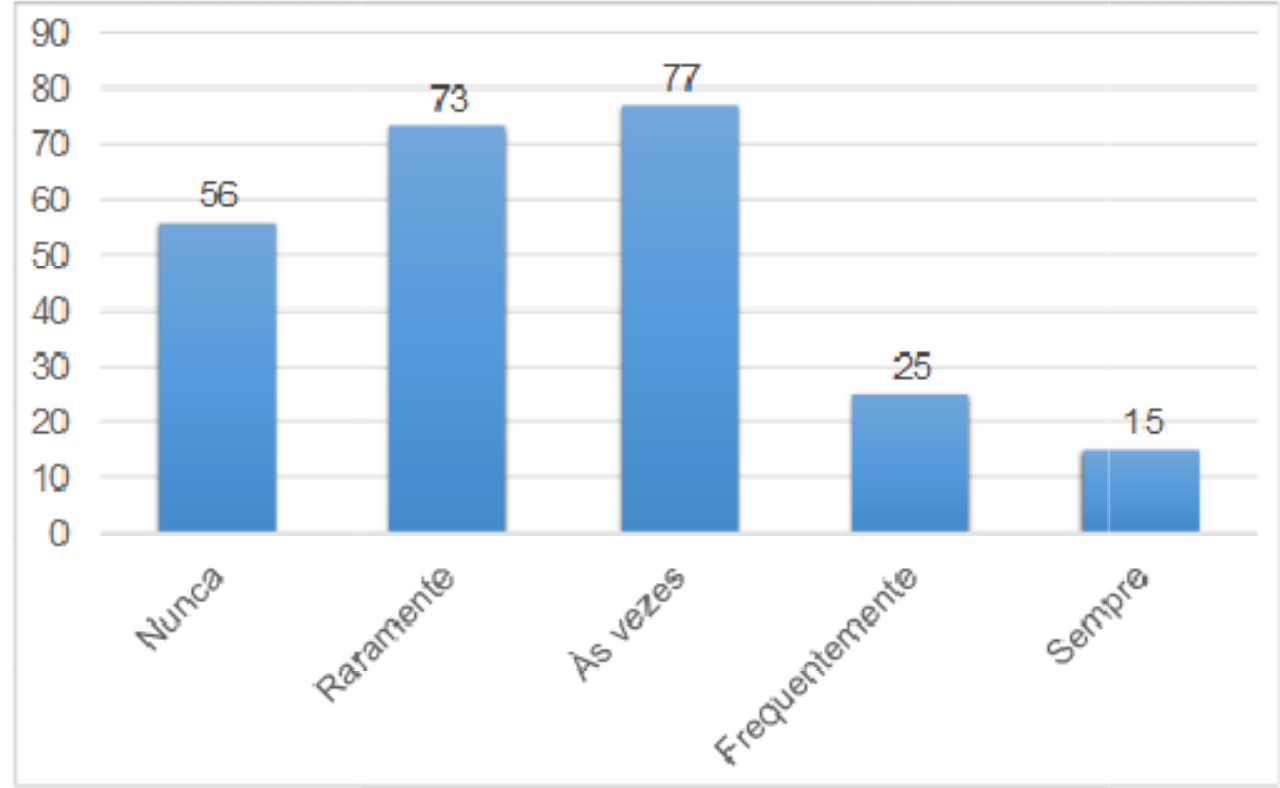

FONTE: Elaborado pelos autores (2018).

Comparando a pesquisa de Maia (2014), os resultados referentes a tipos de turismo ainda permanecem semelhantes, são poucos os viajantes que compartilham de suas experiências com outros indivíduos.

\subsection{Análise do processo de tomada de decisão dos respondentes a partir do CGU}

O processo de tomada de decisão envolve diversos fatores internos e externos, alguns dos fatores externos podem ser observados no gráfico 8 , que mostra quais são os tipos de comentários de viagens na Internet que influenciam suas decisões.

É possível notar que os respondentes se preocupam mais com o custo e benefício das viagens, sendo $70 \%$ da amostra, e $52 \%$ afirmam que são as indicações de atrativos que fornecem informações sobre os locais onde o respondente pode ir visitar.

Embora os comentários sobre segurança estejam em terceiro lugar (com percentual de $42 \%$ ), é um aspecto de extrema importância na viagem, pois a segurança contribui para uma experiência melhor no destino. Outros $39 \%$ da amostra buscam comentários com imagens, já acessibilidade possui percentual de $13 \%$.

Além das opções contidas no instrumento de coleta de dados, foi possível verificar outros tipos de comentários buscados para a tomada de decisão do viajante, tais como: limpeza do destino, clima do local, gastronomia, transportes locais oferecidos e localização. 
GRÁFICO 8 - Tipos de CGU procurados para tomada de decisão.

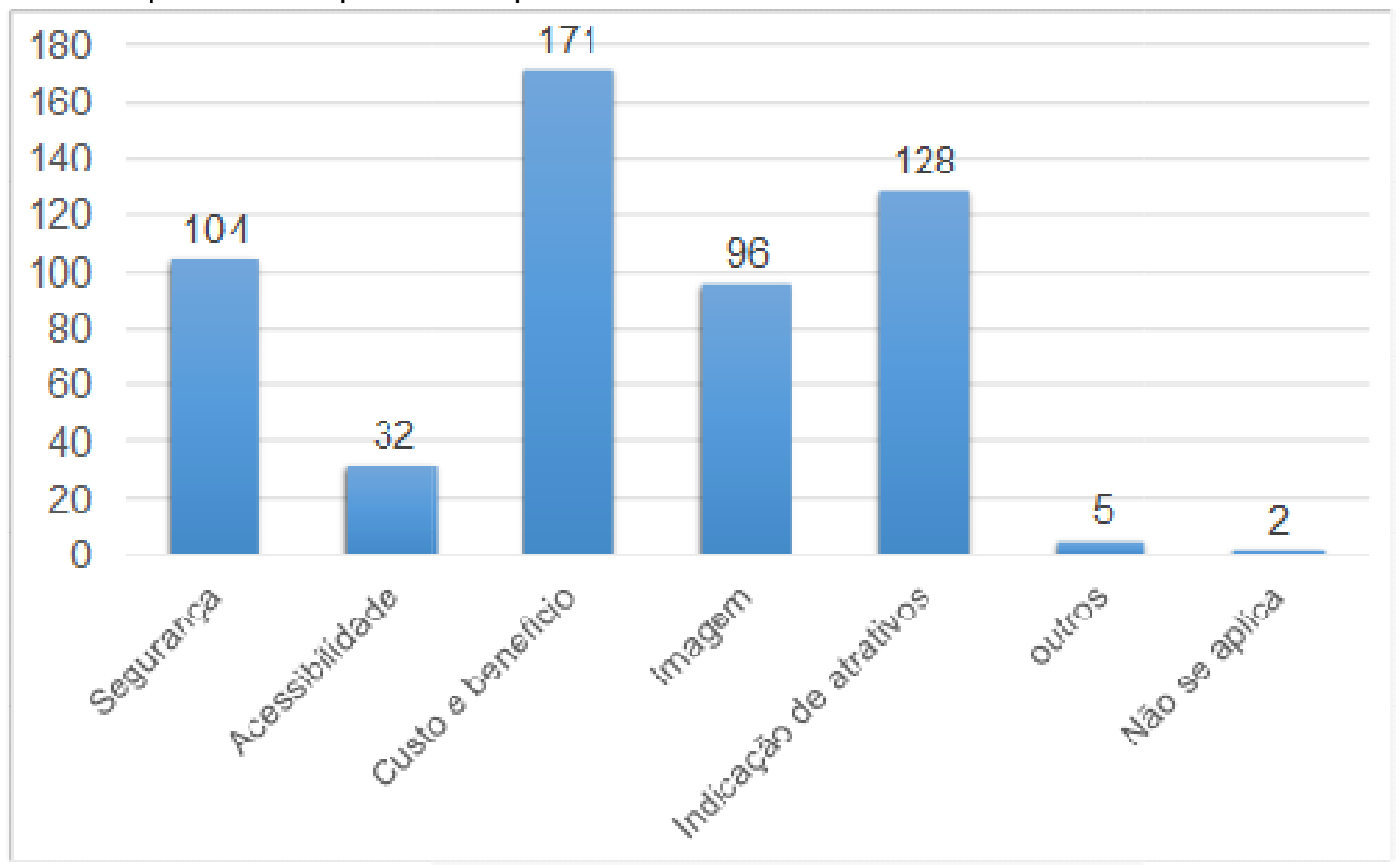

FONTE: Elaborado pelos autores (2018).

A análise do processo de tomada de decisão a partir dos CGU permite estabelecer relações com a teoria de Cooper et al. (2007) que apresenta as etapas do processo de tomada de decisão. O gráfico 8 se enquadra, por exemplo, no nível de envolvimento que o viajante possui com o destino, buscando informações cruciais para a escolha de um destino. Identifica e avalia as alternativas, observando se as características encontradas se encaixam as suas necessidades e recursos disponíveis. Após essas análises, o viajante decide se irá ou não realizar sua viagem.

Relacionando os resultados da pesquisa com a figura 1 de Horner e Swarbooke (2002) sobre os fatores externos e internos influenciadores na decisão de férias, pode-se observar que os comentários buscados pelos respondentes para a tomada de decisão de viagem se enquadram nos fatores internos e externos, como atitudes, opiniões e percepções, clima da destinação, disponibilidade de renda e saúde (a qual se encaixa na acessibilidade).

Vale lembrar que o processo de decisão não se esgota na aquisição de um produto ou serviço, pois, ao longo de sua viagem, o consumidor segue tomando decisões sobre outros serviços como alimentação, hospitalidade e, até mesmo, outros locais para visita (HORNER; SWARBROOKE, 2002).

Estes conceitos sobre decisão de compra (COOPER et al., 2007; HORNER e SWARBROOKE, 2002) possuem pontos que se relacionam com os CGUs na medida em que as informações dos comentários podem contribuir para o aumento do conhecimento do viajante e, consequentemente, para uma tomada de decisão mais consciente sobre o destino e/ou atrativo turístico.

Uma das principais contribuições desta pesquisa está em constatar que os CGUs auxiliam no processo de tomada de decisão ao indicar informações sobre custo/benefício, indicações de atrativos, aspectos sobre a imagem e a segurança do local. Estas informações podem ser utilizadas nas etapas do processo decisório de Identificação e Avaliação de Alternativas. Os resultados empíricos mostram que, nestas etapas, os viajantes observam (em média) até quinze comentários em aproximadamente duas horas de análise de comentários. Portanto, este processo de análise dos CGUs contribui para a Etapa de Decisão.

As respostas da pesquisa podem ser relacionadas com o argumento que a recomendação "boca a boca" virtual é utilizada por $93 \%$ dos respondentes. Destes, $85 \%$ acreditam que os CGUs influenciam as pessoas no processo decisório no que se refere ao turismo, reduzindo a insegurança gerada pela intangibilidade dos serviços.

\section{CONSIDERAÇÕES FINAIS}

O presente trabalho teve como objetivos descrever o perfil dos respondentes, analisar a forma de utilização do CGU e analisar as variáveis que influenciam no processo de tomada dos respondentes a partir do CGU. Estudos apontados nesta pesquisa mostraram respostas semelhantes, porém há um crescimento da influência dos CGU sobre os consumidores. 
A análise de dados possibilitou a caracterização do perfil sociodemográfico, quanto ao gênero, notou-se a predominância de respondentes mulheres, com idade entre 21 e 30 anos. Possuem ensino superior, são de classe "E", recebem até dois salários mínimos e residem no Rio Grande do Sul. Foi realizada uma análise estatística descritiva, a qual permitiu atingir todos os objetivos propostos, respondendo à pergunta de pesquisa.

Os resultados obtidos nesta pesquisa apontaram que a maioria dos viajantes possui experiência com Internet há mais de 5 anos e já utilizaram comentários de viagens, porém nem todos os respondentes acreditam que o CGU possa influenciar nas suas decisões. Também se notou a predominância de respondentes que praticaram turismo de sol e praia e cultural, havendo outros tipos de turismo praticados, mas em menor percentual.

Conclui-se que, embora os respondentes busquem CGU, os mesmos estão visualizando menor quantidade de comentários e escolhendo os destinos em um curto espaço de tempo. Pôde-se notar que alguns sites e redes sociais vêm ganhando força, se tornando cada vez mais presentes na busca dos respondentes por um destino de viagem.

Foi observado que os respondentes não se preocupam tanto em repassar suas experiências, mas buscam informar-se sobre outras experiências para escolher um destino. Ao analisar a frequência de uso de comentários, foi concluido que os respondentes são mais influenciados do que influenciadores devido à pouca frequência de compartilhamento de experiências após suas viagens.

Com relação aos fatores externos que influenciam na tomada de decisão, esta pesquisa contribui para identificar outros fatores externos que podem ser adicionados na listagem da figura 1. Entre estes fatores constatados, observa-se que o custo benefício se sobressai entre as outras opções de comentários escolhidos para decidir viajar a um local.

A contribuição desta pesquisa está nas relações (teóricas e empíricas) entre CGUs, o processo de tomada de decisão e as relações. Todavia, com o ineditismo desta pesquisa, foram encontradas algumas limitações como referencial bibliográfico voltado para o consumidor, tanto nacionais como internacionais, dificultando a construção do referencial deste estudo.

A partir dos resultados encontrados nesta pesquisa, entende-se que seriam relevantes novos estudos sobre CGU, com técnicas diferentes como entrevistas semiestruturadas ou grupos focais, determinando um tipo de turismo com um destino específico, para verificar se a escolha de cada segmento turístico e destino é influenciada de modo diferente. Sugere-se incluir outras fontes de informação online utilizadas, tais como: Instagram, Mochilando, Airbnb, Convention Bureau, E-Dreams y Tubillete, Skyscanner, Mochileiros e Peixe Urbano para novos estudos sobre Conteúdo Gerado pelo Usúario.

\section{REFERÊNCIAS}

ANDRADE, Camila de Albuquerque. "boca-a-boca" eletrônico positivo: motivos que influenciam sua prática nas redes $\quad$ sociais. $2014 . \quad$ Monografia. $\quad$ Disponível em <https://monografias.ufrn.br/jspui/bitstream/123456789/800/1/CamilaAA Monografia.pdf> Acesso: 22 ago.2016.

ARRIGARA, Manuel; LEVINA, Natalia. Social dynamics in online cultural fields. ICIS 2008 Proceedings, p. $120,2008$. Disponível em <http://aisel.aisnet.org/cgi/viewcontent.cgi?article=1097\&context=icis2008> Acesso em: 03 set. 2016.

BARBOSA, Fábia Fonseca. O turismo como um fator de desenvolvimento local e/ou regional/Tourism as a local and/or regional development factor. Caminhos de Geografia, v. 6, n. 14, 2005.

BRASIL, Ministério do Turismo. Uso da Internet na escolha dos destinos cresce 68\%. 2014. Disponível em: <http://www.brasil.gov.br/turismo/2014/10/uso-da-internet-na-escolha-dos-destinos-cresce-68>. Acesso em: 15 ago. 2016.

BOARIA, Francieli. $O$ e-commerce nos meios de hospedagem: Principais ferramentas utilizadas pelas redes hoteleiras no Brasil. 2013. 193 f. Dissertação (Mestrado) - Curso de Turismo e Hotelaria, Universidade do Vale do Itajaí, Balneário Camboriú, 2013.

CARVÃO, Sandra. Embracing user generated content within destination management organizations to gain a competitive insight into visitors' profiles.Worldwide Hospitality and Tourism Themes, v. 2, n. 4, p. 376-382, 2010.

COOPER, Chris; FLETCHER, John; FYALL, Alan; GILBERT, David; WANHILL, Stephen.Turismo Princípios e Práticas. 3. ed. São Paulo: Bookman, 2007.

FREITAS, Henrique; OLIVEIRA, Mírian; SACCOL, Amarolinda Zanela; MOSCAROLA Jean. O método de pesquisa survey. Revista de administração, v. 35, n. 3, p. 105-112, 2000.

HORNER, Susan; SWARBROOKE, John. O comportamento do consumidor no turismo. São Paulo: Aleph, 2002.

HAIR, Joseph; BLACK, William; BABIN, Barry; ANDERSON, Rouph; TATHAN, Ronald. Análise multivariada de dados. Bookman Editora, 2009.

KIETZMANN, Jan; HERMKENS, Kristopher; MCCARTHY, lan. Social media? Get serious! Understanding the functional building blocks of social media. Business Horizons, 2011. Disponível em <http://busandadmin.uwinnipeg.ca/silvestrepdfs/PDF06.pdf.> Acesso em 03 jun. 2016. 
LEHMANN, Rafaela Levay. Estudo sobre a influência das mídias sociais no processo de compra de serviços turísticos. 2013. 78 f. Dissertação (Mestrado) - Curso de Marketing e Cadeia de Valor, Centro Universitário de Brasília, Brasília, 2013.

LIMA JÚNIOR, Josivaldo Atanásio; MENDES FILHO, Luiz. CGU na internet: principais conceitos e estudos bibliográficos no turismo. In: Seminário de Pesquisa do Centro de Ciências Sociais Aplicadas, 2015, Natal. XX Seminário de Pesquisa do Centro de Ciências Sociais Aplicadas, 2015.

LIMA JÚNIOR, Josivaldo Atanásio; MENDES FILHO, Luiz; SILVA, Gislainy Laíse; SOUZA, Jackson. Comentários de Viagem na Internet Na Escolha de um Destino Turístico: Um Estudo Baseado nas Teorias do Comportamento Planejado e Aceitação Tecnológica. Turismo-Visão e Ação, v. 18, n. 2, p. 300-326, 2016. Disponível em <http://siaiap32.univali.br/seer/index.php/rtva/article/view/8869/4954> Acesso em: 23 ago. 2016.

LIMA JÚNIOR, Josivaldo Atanásio; MENDES FILHO, Luiz. CGU Na Internet: Principais Conceitos e Estudos Bibliográficos no Turismo in: Seminário de Pesquisa do CCSA/UFRN, XX, 2015, Natal/RN.

MAIA, Susana. Processo de decisão de compra do turista português relativamente ao destino turístico. 2014 . $121 \mathrm{f}$. Tese de Doutorado - Curso de Gestão de Marketing. Escola Superior de Aveiro, Portugal, 2014.

MARUJO, Maria Noémi. A Internet como novo meio de comunicação para os destinos Turísticos: O caso da llha da Madeira. 2008.

MENDES FILHO, Luiz Augusto Machado; DE CARVALHO, Manuela Santos Dantas. Factores que influyen en el uso del contenido generado por el usuario en Internet: Un estudio preliminar con viajeros brasileños.Estudios y perspectivas en

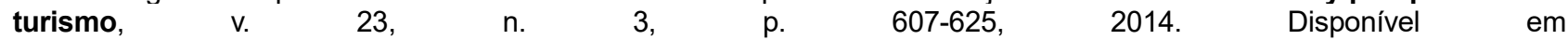
<https://repositorio.ufrn.br/jspui/bitstream/123456789/19053/1/FactoresInfluyenUso 2014.pdf> Acesso em: 20 ago. 2016.

MENDES FILHO, Luiz Augusto Machado; RAMOS, Anatália Saraiva Martins. Estratégia Empresarial E Tecnologia De Informação No Turismo. Revista da Farn, Natal, v. 1, n. 2, p.37-54. 2002.

PEREIRA, Gisele Silva. Comportamento do consumidor no turismo: tipologias e processo de tomada de decisão nas compras. In: III Seminário de Pesquisa em Turismo do Mercosul, 2005, Caxias do Sul - RS. III Seminário de Pesquisa em Turismo do Mercosul, 2005.

SILVA, Danilo Serafim da; MENDES-FILHO, Luiz.Uma análise preliminar do uso de comentários na Internet na escolha de um destino de viagem.Turismo: Estudos e Práticas, Mossoró (RN), v. 2, n. 2, p. 174-195, 2013. Disponível em <http://periodicos.uern.br/index.php/turismo/article/viewFile/859/465> Acesso em: 20 ago. 2016.

SILVA, Marcela Martins; MENDES FILHO, Luiz. Intenção de uso de comentários de viagem online na escolha de um meio de hospedagem: Fatores influenciadores. Revista Brasileira de Pesquisa em Turismo, São Paulo, v. 8 , n. 3, p.419-434, 21 nov. 2014. ANPTUR - Associação Nacional de Pesquisa e Pós-Gradução em Turismo. http://dx.doi.org/10.7784/rbtur.v8i3.805. Disponível em: <https://www.rbtur.org.br/rbtur/article/view/805/650>. Acesso em: 02 nov. 2016.

SILVA, Elizabete Varela da; MENDES FILHO, Luiz. Internet e redes sociais no ambiente de trabalho: Uma análise com funcionários do setor hoteleiro da cidade de Natal (Rio Grande do Norte, Brasil).Turismo \& Sociedade, Curitiba, v. 8, n. 2, p.321-341, maio 2015. Disponível em: <http://revistas.ufpr.br/turismo/article/viewFile/39071/26479>. Acesso em: 20 ago. 2016.

SILVA, Wagner Amaral e; TEIXEIRA, Rivanda Meira.Adoção de Tecnologia da Informação pelas Micro e Pequenas Empresas do Setor Hoteleiro de Sergipe. Revista Brasileira de Pesquisa em Turismo, São Paulo, v. 8, n. 1, p. 59-77, 2014. Disponível em <https://www.rbtur.org/rbtur/article/view/605/629> Acesso em: 20 ago. 2016.

SOUSA, Carina. A influência da Internet na escolha de um destino turístico. Cogitur, Journal of Tourism Studies, n. 5 , 2014. Disponível em <http://revistas.ulusofona.pt/index.php/jts/article/view/4430/2991> Acesso em 22 ago. 2016.

TERRA, Carolina Frazon. Usuário-mídia: a relação entre a comunicação organizacional e o conteúdo gerado pelo internauta nas mídias sociais. 2011. Tese de Doutorado. Universidade de São Paulo.

TOMAS, Robson Nogueira; MESCHGRAHW, Rodolpho Pierre; ALCANTARA, Rosane Lúcia Chicarelli. As Redes Sociais e o Comportamento de Compra do Consumidor: O Reinado do" boca-A-Boca" Está de Volta?.REMark, v. 11, n. 2, p. 124, 2012. 
